\title{
Development of a Flavor Fingerprint by Gas Chromatography Ion Mobility Spectrometry with Principal Component Analysis for Volatile Compounds from Eucommia ulmoides Oliv. Leaves and its Fermentation Products
}

\begin{abstract}
Zhihong Wang, ${ }^{\mathrm{a}, \mathrm{b}}$ Mijun Peng, ${ }^{\mathrm{a}, *}$ Zhigang She, ${ }^{\mathrm{b}, *}$ Minglong Zhang, ${ }^{\mathrm{a}}$ and Qiuling Yang ${ }^{\mathrm{a}}$
Data obtained with gas chromatography coupled with ion mobility spectrometry (GC-IMS) was explored to investigate the characteristics of volatile compounds from edible fungus, from Eucommia ulmoides Oliv. leaves (EUI) that served as growth medium, and from their fermentation products. A total of 162 signal peaks were found, of which 68 compounds were identified, including alcohols, aldehydes, ketones, acids, and esters. There were differences in the volatile constituents of the edible fungi. EUI also contained special volatile components. The volatile components in the fermentation product were different compared to the raw material, and the difference in composition and content of the characteristic compounds was also obvious. The best classification performance was obtained by principal component analysis (PCA) based on the signal intensity of the characteristic volatile compounds. The results clearly showed that the samples (edible fungi, EUl and fermentation products) in a relatively independent space would be well distinguished. This further illustrated that the composition and content of volatile components of EUI could be changed by different microbial strains through biofermentation technology. Combining the signal intensity of the flavor substance, the difference was also clearly observed. This result suggested that the flavor compounds fingerprint could be established by GC-IMS and PCA.
\end{abstract}

Keywords: Eucommia ulmoides Oliv. leaves; Gas chromatography-ion mobility spectrometry;

Fermentation product; Characteristic volatile compounds; Principal component analysis

Contact information: a: Guangdong Provincial Key Laboratory of Emergency Test for Dangerous Chemicals, Guangdong Institute of Analysis (China National Analytical Center Guangzhou), Guangdong Academy of Sciences, Guangzhou, 510070, China; b: School of Chemistry, Sun Yat-Sen University, Guangzhou 510275, China;

*Corresponding authors: pengmj163@163.com; cesshzhg@mail.sysu.edu.cn

\section{INTRODUCTION}

Ion mobility spectrometry (IMS) technology was developed in recent years and was initially used for rapid detection of drugs, explosives, and chemical agents (Shvartsburg 2010; Armenta et al. 2011). The working principle of IMS is that the sample to be tested is vaporized by the ion source and becomes a gaseous molecule, which is chemically ionized and carries a certain amount of electric charge. Then, different target ions will produce corresponding ion spectra in the electric field. This method has the advantages of fast detection speed and high sensitivity (Karpas 2013). However, for complex samples systems in food and agricultural products, the analysis process is often limited (Arce et al. 2014). The combination with gas chromatography (GC) technology will overcome the 
limitations of IMS separation efficiency, and at the same time give full play to the advantages of different instruments (Bunkowski et al. 2010). Under this condition, the ion mobility spectrum enriches the chemical information obtained by chromatographic separation by drift time information; meantime, the ion mobility spectrum signal response is significantly improved in mass and quantity after pre-separation by GC (Zhang et al. 2016; Garrido-Delgado et al. 2018). The three-dimensional matrix (migration time, retention time, and signal strength) obtained by gas chromatography-ion mobility spectrometry (GC-IMS) provides richer chemical information for more comprehensive data processing (Garrido-Delgado et al. 2012; Hajialigol et al. 2012; Zhang et al. 2016; Garrido-Delgado et al. 2018). Research results show that GC-IMS technology combined with chemometric methods is being gradually applied in the field of food testing and natural active ingredient analysis (Fink et al. 2014; Gallegos et al. 2015; Garrido-Delgado et al. 2015a, 2015b; Gallegos et al. 2017; Gerhardt et al. 2017, 2018; Mochalski et al. 2018). In this process, principal component analysis (PCA) is a commonly used feature for extraction and application of data dimensionality reduction in chemometrics (Jourdren et al. 2017; Pu et al. 2019).

For the GC-IMS technology, the complex sample is initially separated by GC technology, and then it is analyzed by an IMS detector. This combination technology can greatly improve the accuracy of mixture detection. Additionally, because GC separation is completed in seconds to minutes, while IMS detection time is measured in milliseconds, the detection time is greatly reduced compared with conventional chromatography, so it can meet the needs of the field of rapid analysis. (Politis et al. 2010; Jafari et al. 2012; Liedtke et al. 2018). The sample can be treated by GC prior to testing, which also effectively reduces the effect of humidity on IMS. Finally, a three-dimensional spectrum containing retention time, drift time, and signal strength can be obtained, which also makes the qualitative analysis more accurate. And both GC and IMS can operate under atmospheric pressure, they are easy to operate, and low in cost (Jafari et al. 2012). So the combined technology of GC and IMS has been widely considered.

At present, GC-IMS is considered an important technology for detecting volatile components from complex samples. Meanwhile, volatile components (flavor substances) are an important factor in the popularity of food, consumer acceptance, and are a vital indicator of the difference between different types of food (Cohen et al. 2015; Fang et al. 2017). Microbial conversion is a method with the most potential to improve taste and flavor. Compared with common chemical synthesis technology, this technology has the advantages of high chemical specificity, positional specificity, and stereospecificity. And the simple operation process makes it more economical and environmentally friendly (Akacha and Gargouri 2015). In addition, edible fungi can produce characteristic volatile components through their own metabolism (Vajpeyi and Chandran 2015).

Modern biofermentation technology is based on the fermentation method of traditional Chinese medicine processing and combined with micro-ecological research results and modern microbial engineering technology to form a new sample processing method (Liese and Filho 1999). On the basis of solid fermentation, the bi-directional solidstate fermentation technology of medicinal fungi is studied and developed, this method mainly refers to the use of medicinal plants or residues with active ingredients as a matrix of active ingredients instead of traditional nutrient bases, and the preferred strains are added for microbial transformation, which will form a special fermentation product. In this process, fermentation matrix provides the nutrients required by the fungus and is also affected by the enzymes from the fungus to change its own tissues and components, and to 
produce new flavor substances and active ingredients. It is of great significance to increase the utilization of biomass resources and broaden the scope of its application (Bel-Rhlid et al. 2018).

As is well known, Eucommia ulmoides Oliv. is one of the oldest nourishing herbs in traditional Chinese medicine (He et al. 2014). Eucommia ulmoides leaves (EUl) contain many active ingredients, such as flavonoids, iridoids, lignans, phenylpropanoids, and polysaccharides, which have the effects of lowering blood pressure, regulating blood lipids, preventing osteoporosis, lowering blood sugar, calming nerves, and resisting fatigue. The resources are rich and also have high utilization value (He et al. 2014; Hirata et al. 2014; Zhu and Sun 2018). In recent years, the chemical composition, activity, and bioavailability of EUl have continually been the focus of attention, but there have been relatively few studies on the characteristic volatile components of EUl, especially with the use of GCIMS technology (Hirata et al. 2014). Further, the investigation of volatile components from fermentation product has rarely been reported. It is worth noting that Ganoderma lucidum (GL) strain, Hericium erinaceus (HE) strain, and Griflola frondosa (GF) strain are important edible fungi (Xu et al. 2010; He et al. 2017; Zhao et al. 2017) and have obvious health benefits and medicinal value. Based on the above mentioned, solid-state fermentation of different edible fungi and EUl may produce some interesting results, this phenomenon is worth exploring, and it is also necessary to analyze the characteristic volatile components by GC-IMS technology.

The objective of this study was to first develop a simple and rapid method for the investigation of the characteristic volatile components of EUl, different edible fungi, and their fermentation products using GC-IMS technology. Differences were compared by the fingerprinting of different sample compounds obtained and PCA techniques. Furthermore, some of the marked compounds were identified throughout the spectrum, and the composition and relative content in different samples were analyzed. This would provide a theoretical basis for the development of new fermentation products with special activity.

\section{EXPERIMENTAL}

\section{Materials}

EUl were obtained from Cili Du-zhong Forestry Centre (Zhangjiajie, China). The fresh leaves were dried at $60{ }^{\circ} \mathrm{C}$, and then the sample was prepared and stored at $4{ }^{\circ} \mathrm{C}$ until use.

Ganoderma lucidum (GL) preservation strain (strain number GDMCC5.250), Hericium erinaceus (HE) preservation strain (strain number GDMCC5.66), and Griflola frondosa (GF) preservation strain (strain number GDMCC5.63) were purchased from Guangdong Institute of Microbiology Culture Collection (Guangzhou, China).

All the reagents used in the experiment were of analytical grade. Ultrapure water (Milli-Q Plus system, Millipore, Bedford, MA, USA) was used throughout the work.

\section{Preparation of Fermentation Samples}

The sample of EUl prepared was selected, and then an appropriate amount of water was added until the sample was wetted, and the sample was placed in the cultivation bag after being uniformly stirred. These samples needed to be sterilized at $121{ }^{\circ} \mathrm{C}$. After the sample was cooled to room temperature, under aseptic conditions, GL strain, HE strain, GF strain, or GL-GF complex strain were inoculated into the fermentation medium (EUl), 
and the moisture content of the substrate was about $65 \%$. The mixed fermentation system was cultured in the dark at $25 \pm 3{ }^{\circ} \mathrm{C}$ until the mycelium was overgrown with the cultivation bag to stop the fermentation, and the sample was taken out to obtain different fermented fungus substance. These samples were stored in low temperature conditions until analyzed. There were eight kinds of samples in the experiment, which were Ganoderma lucidum microbial strain (GL-M), Hericium erinaceus microbial strain (HE-M), Griflola frondosa microbial strain (GF-M), Eucommia ulmoides leaves (EUl), the Ganoderma lucidum and Eucommia ulmoides leaves fermentation group (GL-EUl-F), the Hericium erinaceus and Eucommia ulmoides leaves fermentation group (HE-EUl-F), the Griflola frondosa and Eucommia ulmoides leaves fermentation group (GF-EUl-F), and the Ganoderma lucidumGriflola frondosa and Eucommia ulmoides leaves fermentation group (GL-GF-EUl-F).

\section{GC-IMS Instrumentation and Analysis Parameters}

The experiments were performed on a GC-IMS prototype manufactured by G.A.S. (Gesellschaft für Analytische Sensorsysteme mbH, Dortmund, Germany) based on an Agilent 6890N gas chromatograph (Agilent Technologies, Palo Alto, CA, USA), coupled to a drift time IMS cell. Analyses for the identification of characteristic volatile compounds of the samples were performed on an IMS commercial instrument (FlavourSpec) from Gesellschaft für Analytische Sensorysteme mbH (G.A.S., Dortmund, Germany) fitted with a non-polar column (FS-SE-54-CB) constituted by $94 \%$ methyl-5\% phenyl-1\% vinylsilicone with a $30 \mathrm{~m}$ length $\times 0.32 \mathrm{~mm}$ and $0.5 \mu \mathrm{m}$ film thickness. The injection rate was $100 \mu \mathrm{L} / \mathrm{s}$, and the carrier flow rate was $5 \mathrm{~mL} / \mathrm{s}$.

For analysis, $1.0 \mathrm{~g}$ of different samples that needed to be analyzed (edible fungi, EUl, and its different fermentation products) were placed in a $20-\mathrm{mL}$ vial that was closed with magnetic caps. After $20 \mathrm{~min}$ of incubation at $80{ }^{\circ} \mathrm{C}, 200 \mu \mathrm{L}$ of sample headspace was automatically injected by means of a heated syringe $\left(80^{\circ} \mathrm{C}\right)$ into the heated injector $(80$ ${ }^{\circ} \mathrm{C}$ ) of the GC-IMS equipment. After injection, the nitrogen gas $(99.999 \%)$ used as carrier gas, passed through the injector inserting the sample into the gas column, which was heated at $40{ }^{\circ} \mathrm{C}$ for timely separation. Then, the analytes were eluted in the isothermal mode and driven into the ionization chamber for ionization, prior to spectrometric detection. Molecules were ionized using a tritium source $(6.5 \mathrm{keV})$, and the resulting ions were driven to the drift region via a shutter grid (Bradbury and Nielson design). The drift tube was 5 $\mathrm{cm}$ long and operated at a constant voltage of $400 \mathrm{~V} / \mathrm{cm}$, a temperature of $45^{\circ} \mathrm{C}$, and a drift gas flow rate of $250 \mathrm{~mL} / \mathrm{min}$ (nitrogen). Data were acquired via the spectrometer's builtin computer. Each sample spectra had an average of 32 scans.

\section{Data Analysis}

The study of specific volatile compounds to identify them was realized by the software LAV version 2.0.0 from G.A.S. (Dortmund, Germany). Based on the use of the information included in the whole spectral fingerprint, raw IMS data were converted to .csv format using LAV software. Moreover, GC-IMS Library Search software supplied by G.A.S. (Dortmund, Germany) was employed to identify unknown compounds. Chemometric processing of the IMS data was performed with SIMCA-P 14.0 (Umetrics, Umea, Sweden). The processing technique mainly included principal component analysis (PCA). Data were initially subjected to PCA to reduce their dimensions and apply the classifying procedure to a smaller subspace (Garrido-Delgado et al. 2011), and the minmax normalization method was used to perform PCA. 


\section{RESULTS AND DISCUSSION}

\section{GC-IMS Topographic Plots from Different Samples}

In this study, a simpler and quicker GC-IMS technology was proposed for the discrimination of the composition of EUl according to the volatile components. The five batches of Eucommia ulmoides samples mentioned above (EUl, GL-EUl-F, HE-EUl-F, GF-EUl-F, and GL-GF-EUl-F) were investigated using this method, and the signal intensity of some representative peaks were observed and analyzed. Simultaneously, corresponding different edible fungi (GL-M, HE-M, and GF-M) were also analyzed by GC-IMS under the same conditions ( $\mathrm{Li}$ et al. 2015). All signal peaks determined in this study were consecutively numbered and in the following either termed by their names or by a number from 1 to 162, which summarized the GC-IMS results. These compounds could be expected to distinguish the differences of the samples (Jünger et al. 2012). Notice that one compound can result in more than one signal or spot (monomer or dimer), depending on the concentration. Spectra at different retention times can be obtained in a topographic plot. For example, the analysis results of the EUl sample is shown in Fig. 1. Different peaks are shown and marked. It was worth nothing that each peak was represented by a spot in the topographic plot (Arroyo-Manzanaresa et al. 2018). There were significant differences in the volatile components of the different samples. Furthermore, this was the first time that some of these target compounds had been studied for EUl samples by Headspace-GC-IMS (HS-GC-IMS).

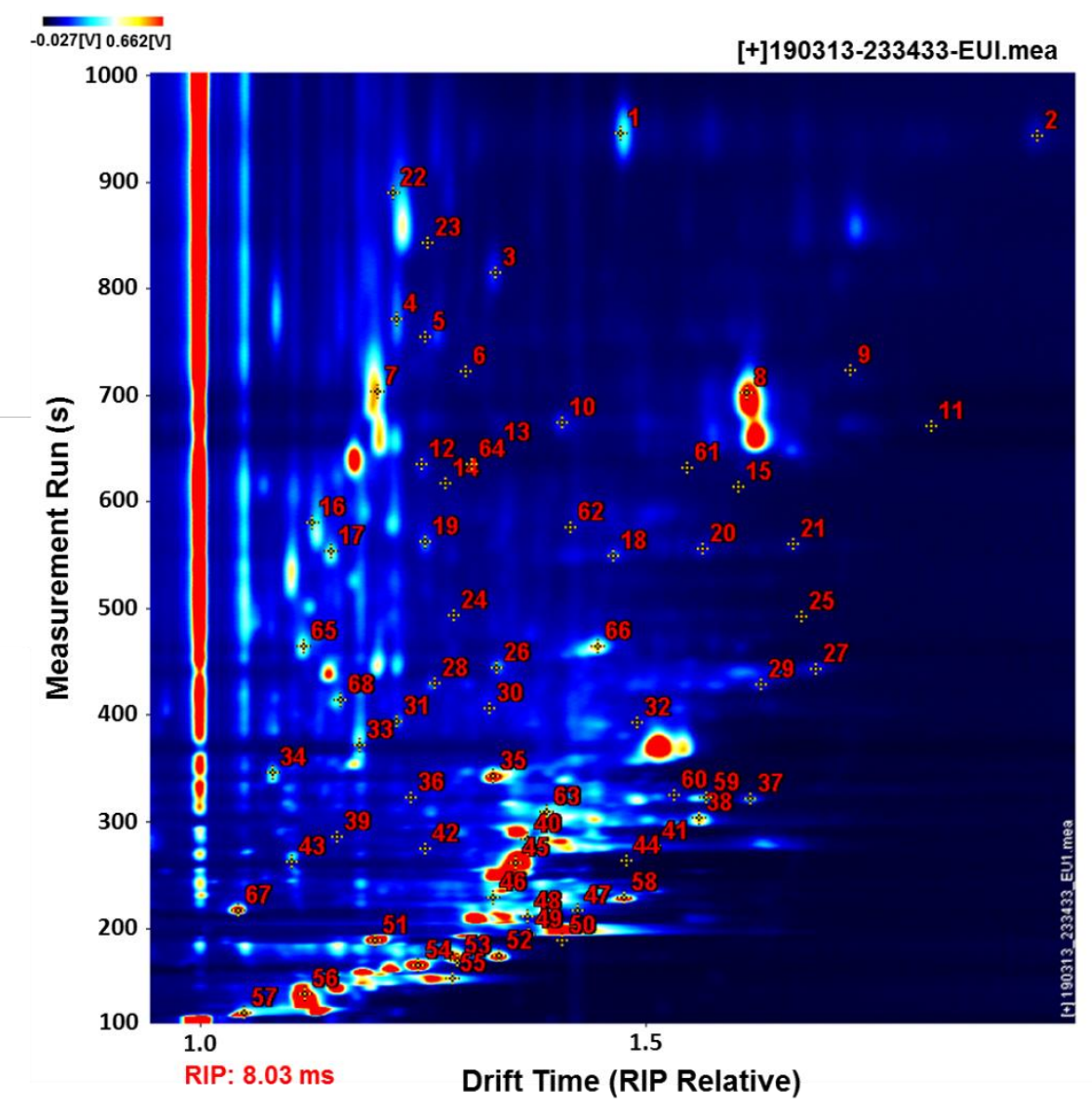

Fig. 1. Imaging of volatile compounds represented by GC-IMS for EUI 


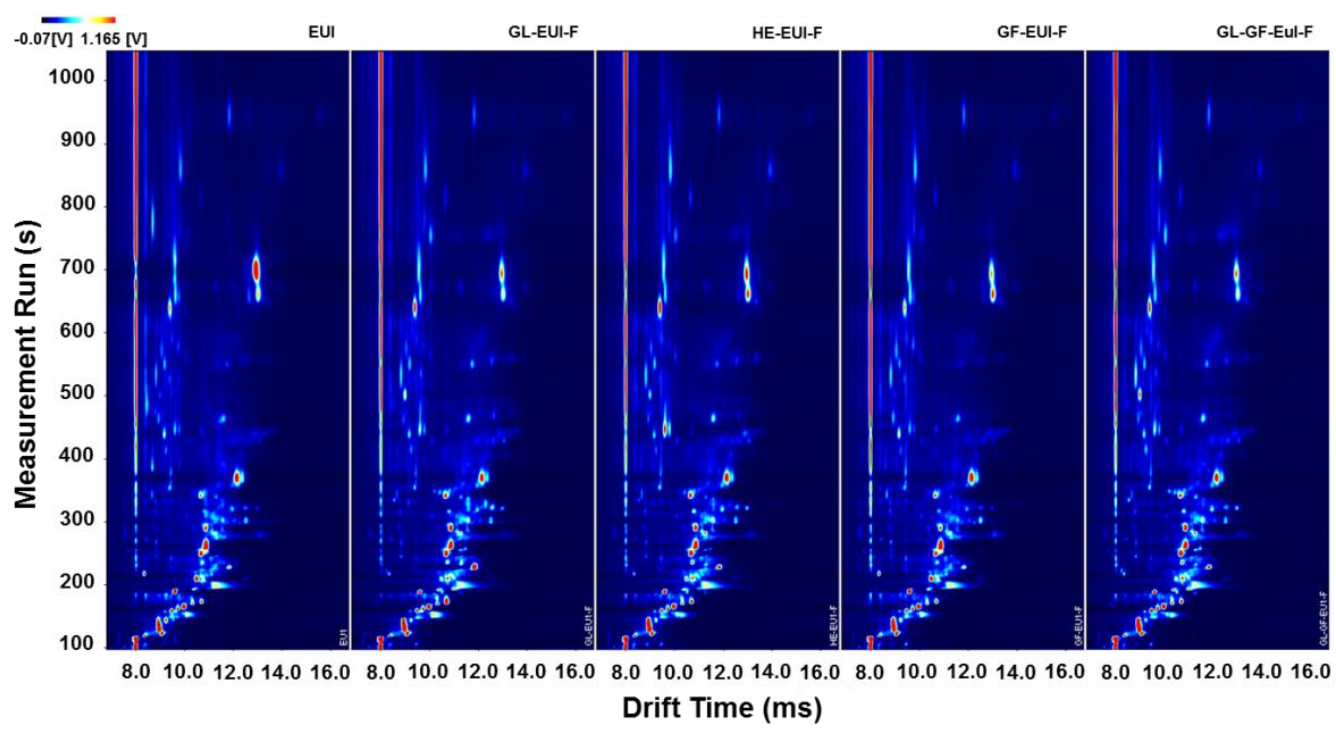

Fig. 2. Comparison of ion migration chromatogram of different samples (edible fungi, and Eucommia ulmoides Oliv. leaves, and its fermentation products)
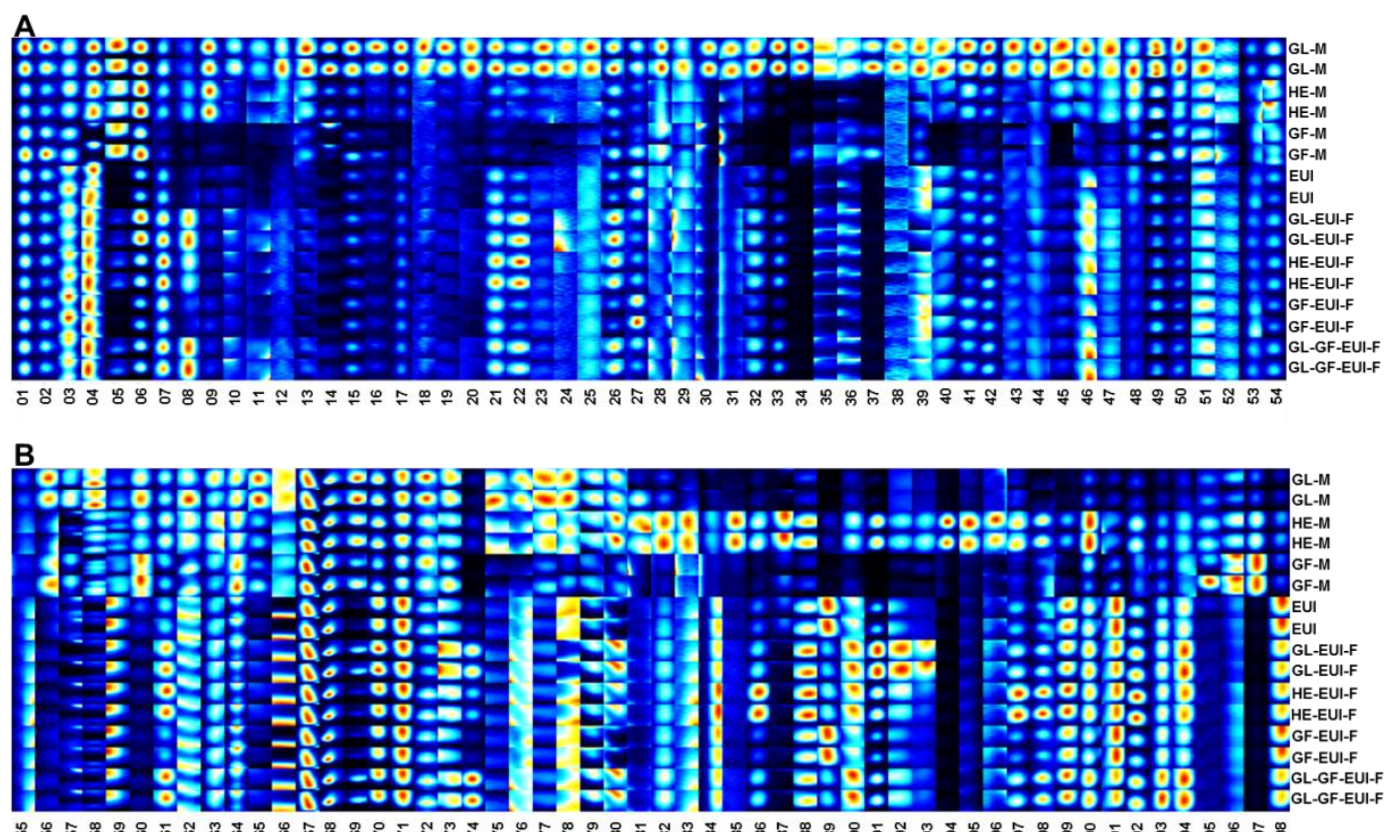

แ้ํำ

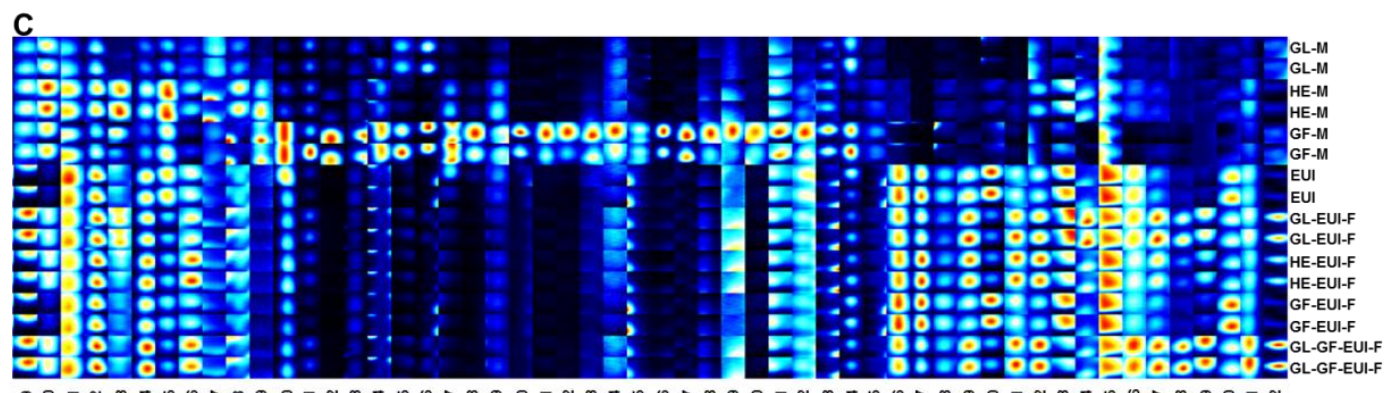

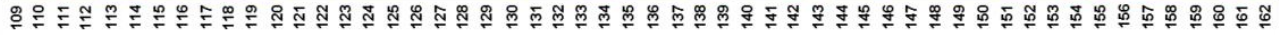

Fig. 3. Gallery plot of the signal peak areas obtained from different sample (edible fungi, and Eucommia ulmoides Oliv. leaves, and its fermentation products) 
Figures 2 and 3 show the topographic plot for different samples. As shown, the different samples analyzed exhibited significant differences in some monomer or dimer ions.

The differences of volatile compounds in EUl and its fermentation products were analyzed by GC-IMS. The data were presented by topographical visualization, where the $\mathrm{Y}$-axis represented the retention time of the gas chromatograph, the $\mathrm{X}$-axis represented the ion migration time for identification, and signal strength represented the relative content of the compound. As shown in Figs. 2 and 3, the composition of the volatile compounds from the different samples was similar, but the signal intensity was slightly different. The ion migration time and the position of the reactive ion peak (RIP) were normalized (Wang et al. 2019). The whole spectrum represented the total headspace volatile compounds of the different samples, including edible fungi and EUl samples. Each point in the spectrum represented a volatile compound. It could be seen that most of the signals appeared in the retention time of 100 to $900 \mathrm{~s}$ and the drift time of 1.0 to $1.8 \mathrm{~ms}$. Color represented the signal intensity of the target substance. Black indicated lower intensity and red indicated higher intensity ( $\mathrm{Li}$ et al. 2019). It can be seen from the figure that a total of 162 characteristic peaks were found from the three edible fungi and different EUl samples by GC-IMS technology. In terms of three edible fungi (GL, HE, and GF), although they had some similar components, the relative content varied greatly, and the difference in the main volatile components was obvious. The results from Fig. 3 showed that different edible fungi had their own unique composition of volatile components and were also well represented in the figure, and it also shown that this detection method could be fully applied to find the differences between different samples. In view of the different chemical composition and flavor differences of different edible fungi, applying them to fermentation treatment, some interesting results may be produced that have important research value. It can also be clearly seen from the figure that for the 162 peaks that were found, the content of some of the three edible fungi was low or even absent. Some of these compounds were found in three edible fungi and EUl materials, but the difference in composition and content of the overall volatile compounds was significant. These results further indicate that through the biotransformation technology, the composition and relative content of edible fungi and EUl could be affected. This method would have an important impact on the new target components, characteristic volatile components, and flavor improvement of the fermentation products. Additionally, it was also meaningful to study the composition and identification of the target volatile compounds.

\section{GC-IMS Topographic Plots from Different Samples Fermented}

Biotransformation technology is currently the most promising method for discovering novel compounds (Liese and Filho 1999). EUl were fermented with different strains, such as GL, HE, GF, and GL-GF complexes. The volatile components of the fermentation product were analyzed by the GC-IMS. As shown in Figs. 2 and 3, the composition and relative content of the volatile compounds in the corresponding fermentation products were changed compared to the raw materials of EUl. It could also be seen from the topographic plots that the relative content of some compounds in edible fungi could be significantly reduced or even disappear through fermentation. The EUl samples also had similar trends, but the number of compounds were less than that of edible fungi. Meanwhile, different novel compounds were produced in the fermentation products based on the different edible fungi, and the composition and relative content of the compounds in the final fermentation product were also significantly different. Compared 
with EUl raw materials, based on the relative peak intensities derived from instrumental software analysis, among them, the content of 10 compounds was reduced, and the content of 23 compounds was increased; the relative content of 57 compounds was comparable to or slightly increased with the raw materials, and 15 compounds were similar to or slightly reduced from the raw materials. In addition, there were 49 compounds in the corresponding fermentation products with a relatively large fluctuation (increased or decreased) under the fermentation conditions of different edible fungi. Obvious changes had not been discovered. This also indicated that different edible fungi could significantly change the composition characteristics of volatile components in EUl samples through solid state fermentation. Choosing the right strain, sample, and fermentation conditions is of great significance for discovering new target compounds and improving the original flavor of the sample. It is worth noting that although the relative content of most of the compounds in the fermentation product changes after fermentation, compared with the EUl, and the changes of some compounds were very obvious, the basic composition of the whole compound was nearly similar to the raw materials. However, compared with the three edible fungi, the volatile components in the fermentation product changed obviously. It can be seen from the figure that a large number of compounds are significantly reduced or disappeared, which further indicates that microorganisms affect their own flavor components during the fermentation process, and that the fermentation substrate also plays an important role in this process. Figures 2 and 3 show that the volatile components in the product after co-fermentation with edible fungi and EUl were not the superposition of the flavors of the two substances but had obvious adjustment and improvement on the original characteristic flavor. The experimental results showed that the IMS technology could efficiently and quickly detect and analyze volatile components in samples. In the process of fermentation, first, the microorganisms pass through a specific fermentation substrate, and their flavor composition would change significantly. Secondly, by using microbial metabolism, the structure and flavor of EUl would also change significantly. Therefore, the selection of suitable microbial strains and fermentation conditions can effectively improve the appearance, functional ingredients, nutritional value, and taste and flavor of the raw material samples.

\section{Analysis of Volatile Compounds Identified from Different Samples}

Flavor quality plays an important role in directing consumers' preference. Therefore, it is necessary to separate and identify volatile components by different chemical methods for the application and development of new food raw materials (Cohen et al. 2015). Based on the analysis results of this study, for the EUl samples with and without fermentation, Fig. 3 shows that a total of 162 signal peaks were discovered by GCIMS. Simultaneously, from the results shown in Table 1, 68 of the characteristic compounds were identified, which mainly contained alcohols, aldehydes, ketones, and esters.

Based on a comprehensive analysis of the different samples by the HS-GC-MS, the volatile composition characteristics of all samples can be obtained according to fingerprint analysis techniques. At the same time, according to the migration time of the IMS, the retention index, and the corresponding database, some compounds can be identified. Due to differences in concentration, some compounds exhibit multiple spots or signals (monomers or dimers) in the spectrum. 
Table 1. GC-IMS Integration Parameters of Volatile Compounds Identified to Distinguish Different Samples

\begin{tabular}{|c|c|c|c|c|c|c|c|}
\hline$\#$ & $\begin{array}{c}\text { Gallery } \\
\text { Plot-area } \\
\text { Label }\end{array}$ & Compound & Formula & $\mathrm{RI}$ & Rt (s) & $\begin{array}{c}\text { Dt (RIP } \\
\text { Relative) }\end{array}$ & Comment \\
\hline 1 & 1 & Nonanal & $\mathrm{C}_{9} \mathrm{H}_{18} \mathrm{O}$ & 1105.9 & 945.36 & 1.474 & Monomer \\
\hline 2 & 2 & Nonanal & $\mathrm{C}_{9} \mathrm{H}_{18} \mathrm{O}$ & 1105.1 & 943.02 & 1.941 & Dimer \\
\hline 3 & 7 & (E)-2-Octenal & $\mathrm{C}_{8} \mathrm{H}_{14} \mathrm{O}$ & 1059.3 & 815.10 & 1.333 & \\
\hline 4 & 82 & Limonene & $\mathrm{C}_{10} \mathrm{H}_{16}$ & 1043.2 & 771.03 & 1.222 & \\
\hline 5 & 8 & $\begin{array}{l}\text { Phenylacet- } \\
\text { aldehyde }\end{array}$ & $\mathrm{C}_{8} \mathrm{H}_{8} \mathrm{O}$ & 1037.1 & 754.65 & 1.255 & \\
\hline 6 & 9 & 1,8-Cineol & $\mathrm{C}_{10} \mathrm{H}_{18} \mathrm{O}$ & 1024.9 & 721.89 & 1.3 & Monomer \\
\hline 7 & 4 & $\begin{array}{l}\text { ( E, E)-2,4- } \\
\text { Heptadienal }\end{array}$ & $\mathrm{C}_{7} \mathrm{H}_{10} \mathrm{O}$ & 1017.5 & 702.39 & 1.201 & Monomer \\
\hline 8 & 120 & $\begin{array}{l}\text { ( E, E)-2,4- } \\
\text { Heptadienal }\end{array}$ & $\mathrm{C}_{7} \mathrm{H}_{10} \mathrm{O}$ & 1017.2 & 701.61 & 1.615 & Dimer \\
\hline 9 & 52 & 1,8-Cineol & $\mathrm{C}_{10} \mathrm{H}_{18} \mathrm{O}$ & 1025.5 & 723.45 & 1.732 & Dimer \\
\hline 10 & 15 & Octanal & $\mathrm{C}_{10} \mathrm{H}_{18} \mathrm{O}$ & 1006.3 & 673.53 & 1.408 & Monomer \\
\hline 11 & 16 & Octanal & $\mathrm{C}_{10} \mathrm{H}_{18} \mathrm{O}$ & 1005.1 & 670.41 & 1.822 & Dimer \\
\hline 12 & 17 & 2-Pentylfuran & $\mathrm{C}_{9} \mathrm{H}_{14} \mathrm{O}$ & 990.7 & 634.53 & 1.251 & Monomer \\
\hline 13 & 18 & 2-Octanone & $\mathrm{C}_{8} \mathrm{H}_{16} \mathrm{O}$ & 997.3 & 650.91 & 1.335 & \\
\hline 14 & 19 & 1-Octen-3-one & $\mathrm{C}_{8} \mathrm{H}_{14} \mathrm{O}$ & 983.4 & 616.59 & 1.277 & \\
\hline 15 & 20 & 1-Octen-3-ol & $\mathrm{C}_{8} \mathrm{H}_{16} \mathrm{O}$ & 982.1 & 613.47 & 1.606 & \\
\hline 16 & 53 & $\begin{array}{l}\text { 5-Methyl-2- } \\
\text { furfural }\end{array}$ & $\mathrm{C}_{6} \mathrm{H}_{6} \mathrm{O}_{2}$ & 967.8 & 579.93 & 1.128 & Monomer \\
\hline 17 & 54 & Benzaldehyde & $\mathrm{C}_{7} \mathrm{H}_{6} \mathrm{O}$ & 956.1 & 553.41 & 1.149 & Monomer \\
\hline 18 & 121 & Benzaldehyde & $\mathrm{C}_{7} \mathrm{H}_{6} \mathrm{O}$ & 954 & 548.73 & 1.466 & Dimer \\
\hline 19 & 21 & $\begin{array}{l}\text { 2-Furanmeth- } \\
\text { anol, 5-methyl- }\end{array}$ & $\mathrm{C}_{6} \mathrm{H}_{8} \mathrm{O}_{2}$ & 960.3 & 562.77 & 1.254 & Monomer \\
\hline 20 & 26 & $\begin{array}{l}\text { 2-Furanmeth- } \\
\text { anol, 5-methyl- }\end{array}$ & $\mathrm{C}_{6} \mathrm{H}_{8} \mathrm{O}_{2}$ & 957.2 & 555.75 & 1.566 & Dimer \\
\hline 21 & 22 & (E)-2-Heptenal & $\mathrm{C}_{7} \mathrm{H}_{12} \mathrm{O}$ & 959.2 & 560.43 & 1.667 & \\
\hline 22 & 55 & Linalool & $\mathrm{C}_{10} \mathrm{H}_{18} \mathrm{O}$ & 1086 & 889.59 & 1.218 & \\
\hline 23 & 85 & Linalool oxide & $\mathrm{C}_{10} \mathrm{H}_{18} \mathrm{O}_{2}$ & 1069 & 842.21 & 1.257 & \\
\hline 24 & 23 & $\begin{array}{c}\text { Methyl } \\
\text { hexanoate }\end{array}$ & $\mathrm{C}_{7} \mathrm{H}_{14} \mathrm{O}_{2}$ & 927.2 & 492.96 & 1.286 & Monomer \\
\hline 25 & 24 & $\begin{array}{c}\text { Methyl } \\
\text { hexanoate }\end{array}$ & $\mathrm{C}_{7} \mathrm{H}_{14} \mathrm{O}_{2}$ & 926.8 & 492.18 & 1.677 & Dimer \\
\hline 26 & 41 & Heptanal & $\mathrm{C}_{7} \mathrm{H}_{14} \mathrm{O}$ & 900.9 & 444.60 & 1.335 & Monomer \\
\hline 27 & 45 & Heptanal & $\mathrm{C}_{7} \mathrm{H}_{14} \mathrm{O}$ & 900 & 443.04 & 1.693 & Dimer \\
\hline 28 & 42 & 2-Heptanone & $\mathrm{C}_{7} \mathrm{H}_{14} \mathrm{O}$ & 892.1 & 429.78 & 1.265 & Monomer \\
\hline 29 & 32 & 2-Heptanone & $\mathrm{C}_{7} \mathrm{H}_{14} \mathrm{O}$ & 891.1 & 428.22 & 1.631 & Dimer \\
\hline 30 & 47 & 1-Hexanol & $\mathrm{C}_{6} \mathrm{H}_{14} \mathrm{O}$ & 876.8 & 405.99 & 1.326 & \\
\hline 31 & 48 & $\begin{array}{l}\text { 3-Methylbut- } \\
\text { anoic acid }\end{array}$ & $\mathrm{C}_{5} \mathrm{H}_{10} \mathrm{O}_{2}$ & 868.7 & 394.29 & 1.223 & Monomer \\
\hline 32 & 81 & $\begin{array}{l}\text { 3-Methylbut- } \\
\text { anoic acid }\end{array}$ & $\mathrm{C}_{5} \mathrm{H}_{10} \mathrm{O}_{2}$ & 867.6 & 392.73 & 1.492 & Dimer \\
\hline
\end{tabular}




\begin{tabular}{|c|c|c|c|c|c|c|c|}
\hline 33 & 3 & 2-Hexen-1-ol & $\mathrm{C}_{6} \mathrm{H}_{12} \mathrm{O}$ & 851.8 & 371.28 & 1.181 & \\
\hline 34 & 123 & 2-Furfural & $\mathrm{C}_{5} \mathrm{H}_{4} \mathrm{O}_{2}$ & 831.1 & 345.54 & 1.084 & Monomer \\
\hline 35 & 88 & 2-Furfural & $\mathrm{C}_{5} \mathrm{H}_{4} \mathrm{O}_{2}$ & 828.8 & 342.81 & 1.33 & Dimer \\
\hline 36 & 43 & Butyl acetate & $\mathrm{C}_{6} \mathrm{H}_{12} \mathrm{O}_{2}$ & 811.1 & 322.72 & 1.239 & Monomer \\
\hline 37 & 33 & Butyl acetate & $\mathrm{C}_{6} \mathrm{H}_{12} \mathrm{O}_{2}$ & 810.1 & 321.56 & 1.62 & Dimer \\
\hline 38 & 49 & Hexanal & $\mathrm{C}_{6} \mathrm{H}_{12} \mathrm{O}$ & 793.6 & 303.81 & 1.562 & \\
\hline 39 & 60 & $\begin{array}{l}\text { 2-Methylprop- } \\
\text { anoic acid }\end{array}$ & $\mathrm{C}_{4} \mathrm{H}_{8} \mathrm{O}_{2}$ & 775.4 & 285.09 & 1.156 & Monomer \\
\hline 40 & 124 & $\begin{array}{l}\text { 2-Methylprop- } \\
\text { anoic acid }\end{array}$ & $\mathrm{C}_{4} \mathrm{H}_{8} \mathrm{O}_{2}$ & 773.1 & 282.75 & 1.369 & Dimer \\
\hline 41 & 77 & 1-Pentanol & $\mathrm{C}_{5} \mathrm{H}_{12} \mathrm{O}$ & 766.7 & 276.32 & 1.512 & Dimer \\
\hline 42 & 50 & 1-Pentanol & $\mathrm{C}_{5} \mathrm{H}_{12} \mathrm{O}$ & 764.9 & 274.56 & 1.255 & Monomer \\
\hline 43 & 64 & Propanoic acid & $\mathrm{C}_{3} \mathrm{H}_{6} \mathrm{O}_{2}$ & 751.6 & 261.69 & 1.105 & Monomer \\
\hline 44 & 125 & $\begin{array}{c}\text { 2-Methyl-1- } \\
\text { butanol }\end{array}$ & $\mathrm{C}_{5} \mathrm{H}_{12} \mathrm{O}$ & 753.7 & 263.64 & 1.481 & \\
\hline 45 & 101 & Propanoic acid & $\mathrm{C}_{3} \mathrm{H}_{6} \mathrm{O}_{2}$ & 750.8 & 260.91 & 1.356 & Dimer \\
\hline 46 & 57 & Acetoin & $\mathrm{C}_{4} \mathrm{H}_{8} \mathrm{O}_{2}$ & 713.1 & 228.34 & 1.33 & \\
\hline 47 & 65 & Pentanal & $\mathrm{C}_{5} \mathrm{H}_{10} \mathrm{O}$ & 696.3 & 216.06 & 1.425 & \\
\hline 48 & 80 & 2-Pentanone & $\mathrm{C}_{5} \mathrm{H}_{10} \mathrm{O}$ & 688 & 210.60 & 1.37 & \\
\hline 49 & 69 & 1-Butanol & $\mathrm{C}_{4} \mathrm{H}_{10} \mathrm{O}$ & 658.4 & 194.22 & 1.371 & \\
\hline 50 & 5 & $\begin{array}{c}\text { 3- } \\
\text { Methylbutanal }\end{array}$ & $\mathrm{C}_{5} \mathrm{H}_{10} \mathrm{O}$ & 645.9 & 188.37 & 1.408 & Dimer \\
\hline 51 & 108 & $\begin{array}{c}\text { 3-Methyl- } \\
\text { butanal }\end{array}$ & $\mathrm{C}_{5} \mathrm{H}_{10} \mathrm{O}$ & 645.9 & 188.37 & 1.198 & Monomer \\
\hline 52 & 6 & Ethyl Acetate & $\mathrm{C}_{4} \mathrm{H}_{8} \mathrm{O}_{2}$ & 608.9 & 173.36 & 1.337 & \\
\hline 53 & 70 & Butanal & $\mathrm{C}_{4} \mathrm{H}_{8} \mathrm{O}$ & 598.9 & 169.65 & 1.291 & \\
\hline 54 & 71 & 2-Butanone & $\mathrm{C}_{4} \mathrm{H}_{8} \mathrm{O}$ & 585.6 & 164.78 & 1.246 & \\
\hline 55 & 73 & Methylpropanal & $\mathrm{C}_{4} \mathrm{H}_{8} \mathrm{O}$ & 552.7 & 152.69 & 1.285 & \\
\hline 56 & 67 & Acetone & $\mathrm{C}_{3} \mathrm{H}_{6} \mathrm{O}$ & 512.3 & 137.87 & 1.119 & \\
\hline 57 & 68 & Ethanol & $\mathrm{C}_{2} \mathrm{H}_{6} \mathrm{O}$ & 464.5 & 120.31 & 1.051 & \\
\hline 58 & 91 & Propyl acetate & $\mathrm{C}_{5} \mathrm{H}_{10} \mathrm{O}_{2}$ & 714.1 & 229.12 & 1.478 & \\
\hline 59 & 92 & 2-Hexanol & $\mathrm{C}_{6} \mathrm{H}_{14} \mathrm{O}$ & 811.1 & 322.72 & 1.57 & \\
\hline 60 & 93 & $\begin{array}{l}\text { Ethyl 2- } \\
\text { ydroxypro- } \\
\text { panoate }\end{array}$ & $\mathrm{C}_{5} \mathrm{H}_{10} \mathrm{O}_{3}$ & 812.6 & 324.28 & 1.534 & \\
\hline 61 & 132 & 2-Pentylfuran & $\mathrm{C}_{9} \mathrm{H}_{14} \mathrm{O}$ & 989.6 & 631.80 & 1.549 & Dimer \\
\hline 62 & 133 & $\begin{array}{c}\text { 5-Methyl-2- } \\
\text { furfural }\end{array}$ & $\mathrm{C}_{6} \mathrm{H}_{6} \mathrm{O}_{2}$ & 966.2 & 576.03 & 1.418 & Dimer \\
\hline 63 & 142 & Butanoic acid & $\mathrm{C}_{4} \mathrm{H}_{8} \mathrm{O}_{2}$ & 798 & 308.49 & 1.391 & \\
\hline 64 & 38 & 3-Octanone & $\mathrm{C}_{8} \mathrm{H}_{16} \mathrm{O}$ & 990.7 & 634.52 & 1.307 & \\
\hline 65 & 148 & 2-Acetylfuran & $\mathrm{C}_{6} \mathrm{H}_{6} \mathrm{O}_{2}$ & 912 & 464.10 & 1.118 & Monomer \\
\hline 66 & 149 & 2-Acetylfuran & $\mathrm{C}_{6} \mathrm{H}_{6} \mathrm{O}_{2}$ & 912.2 & 464.49 & 1.448 & Dimer \\
\hline 67 & 150 & $\begin{array}{c}\text { 1-Propene-3- } \\
\text { methylthio }\end{array}$ & $\mathrm{C}_{4} \mathrm{H}_{8} \mathrm{~S}$ & 697.4 & 216.84 & 1.045 & \\
\hline 68 & 161 & Propylsulfide & $\mathrm{C}_{6} \mathrm{H}_{14} \mathrm{~S}$ & 881.9 & 413.59 & 1.159 & \\
\hline
\end{tabular}


A total of 68 typical target compounds from topographic plots were identified by the GC-IMS database (Table 1). The appreciated visual plots were chosen and shown together by gallery plot for intuitive comparison of different samples. The differences of volatile compounds identified from different fermentation products and raw materials could be observed from the figure, and the fingerprint of each group of samples was also established. In addition to the identified compounds, the differences and composition of non-target volatile compounds can also be presented. As shown in Table 1, a total of 68 characteristic compounds were identified, of which aldehydes were the most and 23 compounds were identified. There were 13 kinds of alcohol compounds and eight kinds of ketones. In addition, seven kinds of acid compounds and ester compounds were found. Besides, 10 other types of compounds were found.

Compared with EUl raw materials, after fermentation treatment, the relative content of (E, E)-2,4-heptadienal, (E)-2-octenal, 2-furanmethanol, 5-methyl-, methyl hexanoate, 2heptanone (monomer and dimer), 1-hexanol, 1-pentanol, limonene, 2-furfural, ethyl 2hydroxypropanoate, and 5-methyl-2-furfural had different degrees of increase. However, the relative content of 3-methylbutanoic acid, 2-methylpropanoic acid, and (E, E)-2,4heptadienal (dimer) had a decreasing trend. More so, 2-pentylfuran was only found in the GF fermentation group. In addition to the GF fermentation group, the compounds 5methyl-2-furanmethanol (dimer) and acetoin showed a significant increase compared with the EUl. However, in the GF fermentation group, the increase of propanoic acid was obviously higher than that of other groups. The peak intensities of acetone, ethanol, butanal, and 2-butanone in each group were substantially similar. In the HE fermentation group, the relative contents of (E)-2-heptenal and linalool were the highest; linalool oxide was a unique component in HE. The signal intensity of 2-pentanone in GL and GL-GF fermentation products was more obvious. The 3-methylbutanal (dimer) was almost absent in the raw material and GF fermentation group, and ethyl acetate was relatively high in the three edible fungi and GL fermentation groups. In the HE group, the signal intensity of (E)2-octenal was more pronounced, and the relative content of phenylacetaldehyde was in the GL and the GL-GF group was higher than in the other groups. Octanal (monomer and dimer), 2-pentylfuran, 2-octanone, 1-octen-3-one, and 1-octen-3-ol were the major volatile components in GL, and the peak intensities in EUl and fermentation products were relatively weak. Propyl acetate, 2-hexanol, and ethyl 2-hydroxypropanoate were relatively more abundant in the GL fermentation group than the other groups. Benzaldehyde (dimer), 2-furfural, 2-methyl-1-butanol, 2-pentylfuran (dimer), and 5-methyl-2-furfural (dimer) were also observed only in the GF group, which could be considered as the main characteristic component of the sample and was of great significance for qualitative sample types. Butanoic acid and 2-acetylfuran were identified in the GF fermentation group, while the signal intensity of 1-propene-3-methylthio was the highest in the raw material and GF fermentation groups, which also indicated that GF does not affect the content of the compound compared to other species.

After the Eucommia leaves were fermented by the GL-GF complex, the relative content of the propylsulfide was the highest. Among the identified compounds, some compounds could be observed in edible fungi, raw materials, and fermentation products, but the signal intensity corresponding to edible fungi was higher than other groups, such as 2-heptanone (dimer), butyl acetate (dimer), and so on. According to the analysis results, although some compounds were not the highest relative content, they could also be considered as representative compounds in EUl, which was basically consistent with previous reports in the literature. At the same time, according to the identified compounds, 
the composition and content of the compounds in different strains were also different. These results were similar to those reported in the literature (Gallegos et al. 2015; Gallegos et al. 2017).

\section{Similarity Analysis of Fingerprint-based on PCA}

All data from GC-IMS were pre-processed independently before the study of ion mobility profiling. To further interrogate the data, a statistical method was required to emphasize variation and to visualize any patterns within the dataset; on that basis, PCA was selected; it is a multivariate statistical analysis model. By determining a few principal component factors to represent many complex and difficult-to-find variables in the original samples, the regularity and difference among the samples could be evaluated according to the contribution rate of the principal component factors in the different samples (Sebzalli and Wang 2001; Li et al. 2019).

In this study, PCA was established using signal intensity to highlight the differences in the volatile compounds from the different samples. The differences of these samples (with or without the three edible fungi) were analyzed by the PCA model. The PCA of the volatile compounds from the different samples is presented in Fig. 4. According to Fig. $4 \mathrm{~A}$, all the samples could be categorized into five different groups. In these figures, a good discrimination was obtained between the edible fungus and EUl samples. It showed the distribution map for the first two principal components determined by PCA, the first two components explained $66 \%$ of variance, component PC1 contributing $43 \%$ and component PC2 contributing 23\%, and a visualization of the data was obtained. These components were thought to show the similarity between the different EUl samples. This result also further confirmed that different samples contain their own unique chemical components

For the samples from EUl and its fermentation products, according to Fig. 4B, all the samples could also be divided into three different groups. The first two components explained $74 \%$ of variance; component PC1 contributing $59 \%$ and component PC2 contributing $15 \%$. Firstly, in terms of the volatile components, the difference between EUl and its fermentation products was obvious. Moreover, EUl raw materials and GF groups did not show a clear separation. It was important to mention that GL was similar to the GLGF group in terms of the volatile components, and the HE group was different from the other groups. This also explained that compared with other fermentation groups, GF had a relatively small effect on EUl, while the HE, GL, and GF-GL groups could significantly change the characteristic volatile components for EUl. It is worth noting that the effects of GL and GL-GF on the EUl sample were similar.

The figure of PCA showed that consistent with the previous analysis results, after the biological fermentation, the characteristic volatile components of EUl would obviously change, and the results produced by different edible fungi also had differences. The volatile components of EUl were significantly changed through fermentation process. Different fermentation strains had different effects on the composition and content of the volatile components.

In this study, GC coupled with IMS equipment was utilized to determine volatile compounds from the fermentation product of EUl with different edible fungus. The importance of using IMS technology in the flavor analysis of the fermentation product of EUl was demonstrated for the first time. The results confirmed the usefulness of IMS as a screening system for distinguishing different samples. The significance of the present work is that it compared the organic volatile components of different fermentation products' abilities to evaluated different fermentation systems, based on the followed two aspects: 
(1) all the information obtained by ion mobility spectra; and (2) the differences in different fermentation systems.
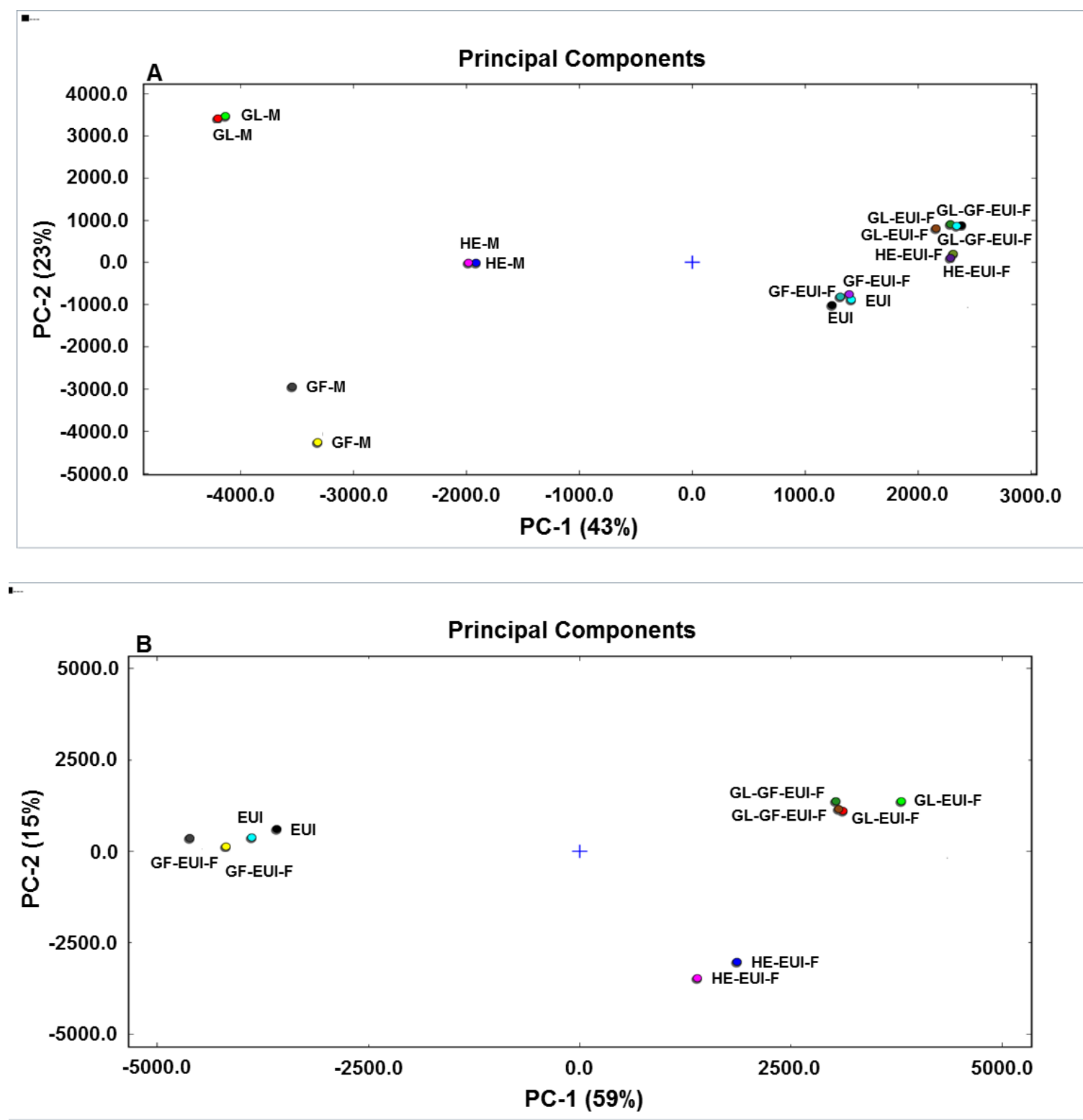

Fig. 4. Principal component analysis based on the signal intensity obtained of volatile compounds from different samples (edible fungi and Eucommia ulmoides Oliv. leaves and its fermentation products). a: all the sample of raw materials and fermentation product; b: EUl sample and its different fermentation products, except for edible fungi

The target compounds, which had been identified using the GC-IMS method, were used to construct a database containing the retention index and drift time. The database would help to quickly identify volatile constituents and efficiently identify new volatile compounds of Eucommia ulmoides fermentation products. Therefore, further work would seek to apply the developed methodology for the detection of E. ulmoides raw materials and new fermentation products would enrich their corresponding databases so that the composition of the volatile compounds from different samples could be more clearly understood. 


\section{CONCLUSIONS}

1. In this study, a simple, fast and reliable method was developed to evaluate the characteristic volatile compounds of edible fungus, Eucommia ulmoides Oliv. leaves (EUl), and its fermentation products by establishing the fingerprint with gas chromatography-ion mobility spectrometry (GC-IMS) and principal component analysis (PCA), which required minimal sample preparation steps and reduced the time required for analysis.

2. The spectral fingerprint approach provided better investigation and classification for the different samples. According to the signal peaks in the spectrum and analysis results, a total of 162 signal peaks were found, of which 68 compounds were identified, including alcohols, aldehydes, ketones, acids, and esters. Meanwhile, fingerprints of characteristic volatile components of different samples were obtained by GC-IMS.

3. Different samples have their own characteristic volatile components. The volatile components of EUl can be changed through biological fermentation. Based on the data of the signal intensity from all the peaks, the best classification performance was obtained by PCA, the results clearly showed that the samples in a relatively independent space would be well distinguished. Additionally, the volatile components of the fermentation products also distributed in the respective characteristic regions, which had differences. This further illustrated that the composition and content of the volatile components of EUl could be significantly changed by different edible fungus through bio-fermentation technology.

\section{ACKNOWLEDGMENTS}

The authors are grateful for the support of the GDAS' Project of Science and Technology Development (2019GDASYL-0103024 and 2019GDASYL-0502003), the Project funded by China Postdoctoral Science Foundation (2019M653099), and the National Natural Science Foundation of China (31660181).

\section{REFERENCES CITED}

Akacha, N. B., and Gargouri, M. (2015). "Microbial and enzymatic technologies used for the production of natural aroma compounds: Synthesis, recovery modeling, and bioprocesses," Food Bioprod. Process. 94, 675-706. DOI: 10.1016/j.fbp.2014.09.011

Arce, L., Gallegos, J., Garrido-Delgado, R., Medina, L. M., Sielemann, S., and Wortelmann, T. (2014). "Ion mobility spectrometry a versatile analytical tool for metabolomics applications in food science," Curr. Metabolomics 2(4), 264-271. DOI: $10.2174 / 2213235 X 03999150212102944$

Armenta, S., Alcala, M., and Blanco, M. (2011). "A review of recent, unconventional applications of ion mobility spectrometry (IMS)," Anal. Chim. Acta. 703(2), 114-123. DOI: 10.1016/j.aca.2011.07.021

Arroyo-Manzanaresa, N., Martín-Gómeza, A., Jurado-Camposa, N., Garrido-Delgadoa, R., Arceb, C., and Arce, L. (2018). "Target vs. spectral fingerprint data analysis of Iberian ham samples for avoiding labelling fraud using headspace-gas 
chromatography-ion mobility spectrometry," Food Chem. 246, 65-73. DOI: 10.1016/j.foodchem.2017.11.008

Bel-Rhlid, R., Berger, R. G., and Blank, I. (2018). "Bio-mediated generation of food flavors-towards sustainable flavor production inspired by nature," Trends Food Sci. Tech. 78, 134-143. DOI: 10.1016/j.tifs.2018.06.004

Bunkowski, A., Maddula, S., Davies, A. N., Westhoff, M., Litterst, P., Bödeker, B., and Baumbach, J. I. (2010). "One-year time series of investigations of analytes within human breath using ion mobility spectrometry," Int. J. Ion Mobil. Spec. 13(3), 141148. DOI: $10.1007 / \mathrm{s} 12127-010-0052-7$

Cohen, G., Rudnik, D. D., Laloush, M., Yakir, D., and Karpas, Z. (2015). "A novel method for determination of histamine in tuna fish by ion mobility spectrometry," Food Anal. Method. 8(9), 2376-2382. DOI: 10.1007/s12161-015-0129-3

Fang, D., Yang, W., Benard, M. K., Zhao, L., An, X., and Hu, Q. (2017). “Comparison of flavor qualities of mushrooms (Flammulina velutipes) packed with different packaging materials," Food Chem. 232, 1-9. DOI: 10.1016/j.foodchem.2017.03.161

Fink, T., Baumbach, J. I., and Kreuer, S. (2014). "Ion mobility spectrometry in breath research," J. Breath Res. 8(2), Article ID 027104. DOI: 10.1088/17527155/8/2/027104

Gallegos, J., Arce, C., Jordano, R., Arce, L., and Medina, L. M. (2017). “Target identification of volatile metabolites to allow the differentiation of lactic acid bacteria by gas chromatography-ion mobility spectrometry," Food Chem. 220, 362-370. DOI: 10.1016/j.foodchem.2016.10.022

Gallegos, J., Garrido-Delgado, R., Arce, L., and Medina, L. M. (2015). "Volatile metabolites of goat cheeses determined by ion mobility spectrometry. Potential applications in quality control," Food Anal. Method. 8(7), 1699-1709. DOI: 10.1007/s12161-014-0050-1

Garrido-Delgado, R., Mercader-Trejo, F., Sielemann, S., De Bruyn, W., Arce, L., and Valcárcel, M. (2011). "Direct classification of olive oils by using two types of ion mobility spectrometers," Anal. Chim. Acta. 696(1), 108-115. DOI:

10.1016/j.aca.2011.03.007

Garrido-Delgado, R., Arce, L., and Valcárcel, M. (2012). "Multi-capillary column-ion mobility spectrometry: A potential screening system to differentiate virgin olive oils," Anal. Bioanal. Chem. 402(1), 489-498. DOI: 10.1007/s00216-011-5328-1

Garrido-Delgado, R., Dobao-Prieto, M. M., Arce, L., Aguilar, J., Cumplido, J. L., and Valcárcel, M. (2015b). "Ion mobility spectrometry versus classical physico-chemical analysis for assessing the shelf life of extra virgin olive oil according to container type and storage conditions," J. Agr. Food Chem. 63(8), 2179-2188. DOI: $10.1021 / \mathrm{jf505415f}$

Garrido-Delgado, R., Dobao-Prieto, M. M., Arce, L., and Valcárcel, M. (2015a). "Determination of volatile compounds by GC-IMS to assign the quality of virgin olive oil," Food Chem. 187, 572-579. DOI: 10.1016/j.foodchem.2015.04.082

Garrido-Delgado, R., Muñoz-Pérez, M. E., and Arce, L. (2018). "Detection of adulteration in extra virgin olive oils by using UV-IMS and chemometric analysis," Food Control. 85, 292-299. DOI: 10.1016/j.foodcont.2017.10.012

Gerhardt, N., Birkenmeier, M., Sanders, D., Rohn, S., and Weller, P. (2017). "Resolution optimized headspace gas chromatography-ion mobility spectrometry (HS-GC-IMS) for non-targeted olive oil profiling," Anal. Bioanal. Chem. 409(16), 3933-3942. DOI: $10.1007 / \mathrm{s} 00216-017-0338-2$ 
Gerhardt, N., Birkenmeier, M., Schwolow, S., Rohn, S., and Weller, P. (2018). "Volatile compound fingerprinting by headspace-gas-chromatography ion-mobility spectrometry (HS-GC-IMS) as a benchtop alternative to $1 \mathrm{H}$ NMR profiling for assessment of the authenticity of honey," Anal Chem. 90(3), 1777-1785. DOI: 10.1021/acs.analchem.7b03748

Hajialigol, S., Ghorashi, S. A., Alinoori, A. H., Torabpour, A., and Azimi, M. (2012). "Thermal solid sample introduction-fast gas chromatography-low flow ion mobility spectrometry as a field screening detection system," J. Chromatogr. A. 1268, 123129. DOI: $10.1016 / j$.chroma.2012.10.010

He, X., Wang, J., Li, M., Hao, D., Yang, Y., Zhang, C., He, R., and Tao, R. (2014). "Eucommia ulmoides Oliv.: Ethnopharmacology, phytochemistry and pharmacology of an important traditional Chinese medicine," J. Ethnopharmacol. 151(1), 78-92. DOI: 10.1016/j.jep.2013.11.023

He, X., Wang, X., Fang, J., Chang, Y., Ning, N., Gao, H., Huang, L., Huang, X., and Zhao, Z. (2017). "Structures, biological activities, and industrial applications of the polysaccharides from Hericium erinaceus (Lion's Mane) mushroom: A review," Int. J. Biol. Macromol. 97, 228-237. DOI: 10.1016/j.ijbiomac.2017.01.040

Hirata, T., Ikeda, T., Fujikawa, T., and Nishibe, S. (2014). "The chemistry and bioactivity of Eucommia ulmoides Oliver leaves," Stud. Nat. Prod. Chem. 41, 225-260. DOI: 10.1016/B978-0-444-63294-4.00008-5

Jafari, M. T., Saraji, M., and Sherafatmand, H. (2012). "Design for gas chromatographycorona discharge-ion mobility spectrometry," Anal. Chem. 84(22), 10077-10084. DOI: $10.1021 / \mathrm{ac} 3025398$

Jourdren, S., Masson, M., Saint-Eve, A., Panouillé, M., Blumenthal, D., Lejeune, P., Deleris, I., and Souchon, I. (2017). "Effect of bread crumb and crust structure on the in vivo release of volatiles and the dynamics of aroma perception," J. Agr. Food Chem. 65(16), 3330-3340. DOI: 10.1021/acs.jafc.7b00287

Jünger, M., Vautz, W., Kuhns, M., Hofmann, L., Ulbricht, S., Baumbach, J. I., Quintel, M., and Perl, T. (2012). "Ion mobility spectrometry for microbial volatile organic compounds: A new identification tool for human pathogenic bacteria," Appl. Microbiol. Biot. 93(6), 2603-2614. DOI: 10.1007/s00253-012-3924-4

Karpas, Z. (2013). "Applications of ion mobility spectrometry (IMS) in the field of foodomics," Food Res. Int. 54(1), 1146-1151. DOI: 10.1016/j.foodres.2012.11.029

Liedtke, S., Seifert, L., Ahlmann, N., Hariharan, C., Franzke, J., and Vautz, W. (2018). "Coupling laser desorption with gas chromatography and ion mobility spectrometry for improved olive oil characterization," Food Chem. 255, 323-331. DOI: 10.1016/j.foodchem.2018.01.193

Liese, A., and Filho, M. V. (1999). "Production of fine chemicals using biocatalysis," Curr. Opin. Biotech. 10(6), 595-603. DOI: 10.1016/S0958-1669(99)00040-3

Li, M., Yang, R., Zhang, H., Wang, S., Chen, D., and Lin, S. (2019). "Development of a flavor fingerprint by HS-GC-IMS with PCA for volatile compounds of Tricholoma matsutake Singer," Food Chem. 290, 32-39. DOI: 10.1016/j.foodchem.2019.03.124

Li, Q., Li, R., Cao, G., Wu, X., Yang, G., Cai, B., Cheng, B., and Mao, W. (2015). "Direct differentiation of herbal medicine for volatile components by a multicapillary column with ion mobility spectrometry method," J. Sep. Sci. 38(18), 3205-3208. DOI: $10.1002 /$ jssc.201500402

Mochalski, P., Wiesenhofer, H., Allers, M., Zimmermann, S., Güntnerc, A. T., Pineau, N., Lederer, W., Agapiou, A., Mayhew, C. A., and Ruzsanyi, V. (2018). "Monitoring 
of selected skin-and breath-borne volatile organic compounds emitted from the human body using gas chromatography ion mobility spectrometry (GC-IMS)," $J$. Chromatogr. B. 1076, 29-34. DOI: 10.1016/j.jchromb.2018.01.013

Politis, A., Park, A. Y., Hyung, S. J., Barsky, D., Ruotolo, B. T., and Robinson, C. V. (2010). "Integrating ion mobility mass spectrometry with molecular modelling to determine the architecture of multiprotein complexes," PLOS ONE 5(8), Article ID 12080. DOI: 10.1371/journal.pone.0012080

Pu, D., Zhang, H., Zhang, Y., Sun, B., Ren, F., Chen, H., and He, J. (2019).

"Characterization of the aroma release and perception of white bread during oral processing by gas chromatography-ion mobility spectrometry and temporal dominance of sensations analysis," Food Res. Int. 123, 612-622. DOI: 10.1016/j.foodres.2019.05.016

Sebzalli, Y., and Wang, X. (2001). "Knowledge discovery from process operational data using PCA and fuzzy clustering," Engi. Appl. Artif. Intel. 14, 607-616. DOI: 10.1016/S0952-1976(01)00032-X

Shvartsburg, A. (2010). "Ion mobility spectrometry (IMS) and mass spectrometry (MS)," Encyclopedia Spectrosc. Spectrom. 23, 1140-1148. DOI: 10.1016/B978-0-12374413-5.00012-9

Vajpeyi, S., and Chandran, K. (2015). "Microbial conversion of synthetic and food waste-derived volatile fatty acids to lipids," Bioresource Technol. 188, 49-55. DOI: 10.1016/j.biortech.2015.01.099

Wang, X., Yang, S., He, J., Chen, L., Zhang, J., Jin, Y., Zhou, J., and Zhang, Y. (2019). "A green triple-locked strategy based on volatile-compound imaging, chemometrics, and markers to discriminate winter honey and sapium honey using headspace gas chromatography-ion mobility spectrometry," Food Res. Int. 119, 960-967. DOI: 10.1016/j.foodres.2019.01.004

Xu, J. W., Zhao, W., and Zhong, J. J. (2010). "Biotechnological production and application of ganoderic acids," Appl. Microbiol. Biot. 87(2), 457-466. DOI: $10.1007 / \mathrm{s} 00253-010-2576-5$

Zhang, L., Shuai, Q., Li, P., Zhang, Q., Ma, F., Zhang, W., and Ding, X. (2016). "Ion mobility spectrometry fingerprints: A rapid detection technology for adulteration of sesame oil," Food Chem. 192, 60-66. DOI: 10.1016/j.foodchem.2015.06.096

Zhao, T., Fan, Y., Mao, G., Feng, W., Zou, Y., Zou, Y., Yang, L., and Wu, X. (2017). "Purification, characterization and antioxidant activities of enzymolysis polysaccharide from Grifola frondosa," Iran. J. Pharm. Res. 16(1), 347-356. DOI: 10.22037/IJPR.2017.1957

Zhu, M. Q., and Sun, R. C. (2018). "Eucommia ulmoides Oliver: A potential feedstock for bioactive products," J. Agr. Food. Chem. 66(22), 5433-5438. DOI: 10.1021/acs.jafc. 8 b01312

Article submitted: May 29, 2020; Peer review completed: August 29, 2020; Revised version received: September 26, 2020; Accepted: September 27, 2020; Published: October 16, 2020.

DOI: 10.15376/biores.15.4.9180-9196 